\title{
O ENSINO DE LITERATURA: novas perspectivas
}

THE TEACHING OF LITERATURE: new perspectives

Celso Leopoldo Pagnan ${ }^{1}$

\begin{abstract}
Resumo
O presente artigo é uma reflexão com base na realização de um Clube de literatura, desenvolvido com setenta alunos do $2^{\circ}$ ano do Ensino Médio de uma Escola Estadual, localizada em Londrina. O Clube teve três objetivos: estabelecer uma leitura sincrônica entre obras literárias de períodos diferentes e de diferentes autores (brasileiros e estrangeiros), levar o aluno a perceber as relações temáticas entre obras diversas e, por meio de textos metalinguísticos, levar o aluno a compreender o processo criativo. Para tanto, selecionamos textos dos seguintes escritores: Machado de Assis, Franklin Távora, Fernando Pessoa, Thomas Mann, Ferreira Gullar e Paulo Leminski. O objetivo geral foi o de refletir a respeito do ensino de literatura e propor novos meios de ensino para a disciplina. O presente artigo é o relato do trabalho em sala de aula, tendo como base teórica os Documentos Oficiais para a área do ensino de literatura, bem como estudiosos diversos (CANDIDO, 1972; JAUSS, 1994; ECO, 1989, entre outros).
\end{abstract}

Palavras-chave: Ensino. Sincronia. Literatura.

\begin{abstract}
This paper is an experience report on the literature club, developed with seventy students of the 2nd year of high school in a public school, located in Londrina. The club had three objectives: to establish a synchronic reading of literary works of different periods and different authors (Brazilian and foreign), leading the student to understand the relationships between different themes and works through metalinguistic texts, take the student to understand the creative process. We selected texts of the following writers: Machado de Assis, Franklin Távora, Fernando Pessoa, Thomas Mann, and Paul Gullar Leminski. The objective was to reflect on the teaching of literature and propose new ways for teaching the discipline. This article is the result of work in the classroom and the theoretical basis for the Official Documents area of literature teaching, as well as several scholars (CANDIDO, 1972; Jauss, 1994; Eco, 1989, and others)
\end{abstract}

Keywords: Education. Synchrony. Literature.

1 O autor é Doutor em Letras pela Universidade Estadual Paulista Júlio de Mesquita Filho (2002) e Professor do Programa de Mestrado em Metodologias para o Ensino de Linguagens e suas Tecnologias - Unopar/Londrina. Email: celso.pagnan@unopar.br 


\section{Introdução}

Vivemos um momento de mudanças em diversos setores da sociedade, e, particularmente, na educação. Nesta, a mudança se dá em especial pela possível utilização da TIC (Tecnologia de Informação e Comunicação), facilitada pelo maior acesso que se tem ao uso das tecnologias computacionais, bem como à expansão da internet e todos seus componentes (redes sociais, blogs, miniblogs etc.). Desse modo, o acesso à informação e a troca ou o compartilhamento de dados se intensificam. Trata-se do princípio da dialogicidade (BAKHTIN, 1997), manifestado agora pelos recursos da nova mídia. No caso específico, essa nova mídia, chamada de mídia-educação (BELLONI, 2005), pelo uso que se passou a fazer de todos esses recursos a serviço do processo ensino/aprendizagem, tem gerado uma nova demanda educacional, a de que o professor seja mais do que um simples transmissor de informações e se transforme em um agente orientador dos estudos, de modo a levar o aluno a, mais do que receber, construir o conhecimento. É o princípio do aprender a aprender de que trata os PCN (Parâmetros Curriculares Nacionais), em sua parte introdutória. (BRASIL, 1997).

Outro aspecto a que se deve fazer referência, para o bem ou para o mal, é o fato de vivermos uma era cada vez mais imediatista, do aqui e agora, da pressão por uma educação ao mesmo tempo de qualidade, porém fast food, por assim dizer. A expressão não se refere a um aspecto qualitativo da educação, e sim ao fato de que nem sempre é possível efetivamente aprofundar um conteúdo em sala de aula, seja pelo pouco tempo disponível (refiro-me em específico neste caso às aulas de literatura, cuja carga horária diminuiu ou foi incorporada às aulas de língua portuguesa como um todo, o que tende a levar o professor a dar um espaço menor à disciplina), seja pela demanda constante de novos conteúdos.

Considerando esse quadro, é preciso que a escola e os conteúdos programáticos mudem, se não em sua totalidade, mas talvez em alguns aspectos, sobretudo os que possibilitarão ao aluno sair efetivamente de sua posição passiva no processo e se tornar parte mais atuante. É o que se vem tratando nos últimos vinte anos em competências a serem desenvolvidas. Como se pode perceber com essa breve contextualização, seria possível desenvolver o presente artigo com base em diferentes correntes teóricas, incluindo o construtivismo de Piaget (2007); porém, o objetivo é outro, no caso refletir sobre o ensino da literatura e a exigência de um novo paradigma no processo ensino/aprendizagem dessa 
disciplina em particular. É bem verdade, de qualquer modo, que os PCN (BRASIL, 1997) tomam por base o construtivismo, cujas referências são a psicologia genética, a teoria sociointeracionista e as explicações da atividade significativa. Porém, não é o caso aqui de dar conta de todas essas correntes teóricas. Quer-se, apenas, indicar caminhos para a reflexão sobre o ensino da literatura.

E, em rigor, as aulas de literatura, podemos afirmar, apresentam uma mesma base há décadas (ou mais de um século). Isto é, o estudante assim que inicia o ensino médio é colocado em contato com o início da literatura de língua portuguesa, leia-se Trovadorismo, e passa a ver os principais escritores e obras a partir desse momento até chegar ao Modernismo, das décadas de 40 e 50 do século XX, quando muito alguns poucos, de acordo com a demanda dos vestibulares, das décadas de 60,70 ou 80 .

Claro que se trata de um conteúdo importante para a compreensão das mudanças por que passou a linguagem literária, bem como para a formação estética do educando. Além, o que é óbvio, de se conhecer o enredo de romances ou a perspectiva sobre os grandes temas presentes em poemas épicos e líricos. O que se quer dizer, inicialmente, é que o ensino da literatura deveria buscar alternativas, para cumprir umas das metas a que fazem referência as Orientações Curriculares para o Ensino Médio (BRASIL, 2006), dotar o educando de um arcabouço teórico capaz de possibilitar a ele o que vem sendo chamado de letramento literário, por referência aos estudos de Kleiman (1995) e Soares (2006).

No caso dos estudantes do ensino médio, sabe-se que eles têm de dar conta das várias escolas literárias e seus respectivos representantes. Porém, é comum aquele aluno que demonstrava grande interesse pelos livros durante o ensino fundamental, poder ter esse interesse diminuído, pois acaba sendo obrigado a ler livros (ainda que com importância estética ou histórica) dissociados da própria realidade imediata. Assim, o trabalho que foi sendo feito ao longo da vida escolar, para que adquira o hábito da leitura pode acabar sendo desfeito, embora sempre haja exceções. É bem verdade, porém, segundo dados da pesquisa Retratos de Leitura, do Instituto Pró-livro, que há um pequeno aumento na quantidade de livros lidos por ano entre alunos do ensino fundamental e os do ensino médio, o que se justificaria pela necessidade de preparação para o vestibular. 


\section{Tabela 1}

\begin{tabular}{|c|c|}
\hline livros habitante/ano & $\mathbf{2 0 1 1}$ \\
\hline Até 4ㅁ & 2,5 \\
\hline 5a a $\mathbf{8} \underline{\mathbf{a}}$ & 3,7 \\
\hline Ens. Médio & 3,9 \\
\hline Superior & 7,7 \\
\hline
\end{tabular}

Fonte: Instituto Pró-livro (2012).

Apesar do número um pouco mais elevado, o fato é que o estudante do ensino médio lê menos de quatro livros inteiros por ano. Isso em média, pois, em rigor, há os que não leem livro algum.

Não se pode dizer que se trata de uma solução definitiva, de uma panaceia, mas um caminho, talvez, seja o de se efetuar um ensino de caráter sincrônico, não diacrônico. Isto é, mais importante que vir paulatinamente do século XIII a meados do século XX, deveria se trabalhar com ênfase maior a atualidade, leia-se: fins do século XX e início do XXI, em paralelo com outros momentos da história literária. Dessa maneira, a fruição estética e a compreensão mais ampla do universo literário poderiam ser mais aceitáveis a esse aluno, que, com um clique tem toda uma série de informações à disposição. Falta-lhe, porém, o principal, ser lapidado para saber escolher, o que nem sempre a escola é capaz de fazer no modelo atual.

O presente artigo tem como uma de suas motivações o que é sugerido pelo PCNEM (BRASIL, 2000, p. 16), onde se lê: "Quando deixamos o aluno falar, a surpresa é grande, as respostas quase sempre surpreendentes”. É resultado de uma pesquisa teórica, bem como de aplicação prática em duas turmas do $2^{\circ}$ ano do ensino médio de um colégio estadual, e tem como objetivo refletir sobre como o aluno percebe aquilo que lhe é ensinado, particularmente três conceitos: a definição de literatura, as funções da literatura e como um escritor cria, em especial, um personagem. Importante frisar que não se quer discutir as teorias em torno desses conceitos, corroborando sua validade ou não, e sim, com base em aplicação prática, refletir sobre o ensino da literatura e a percepção que os alunos têm do objeto literatura.

Tal discussão será feita com base nos estudos de Candido (1972), Jauss (1994), PCN, PCN+ e Orientações Curriculares, além de outros estudiosos que possam dar base à presente pesquisa. Realizadas as considerações teóricas, queremos traçar um diagnóstico da experiência de um clube de literatura, por assim dizer, em sala de aula, em que procuramos 
descrever e analisar como os alunos percebem os três conceitos referidos (definição de literatura, funções e processo criativo), de modo a estabelecer uma leitura sincrônica entre obras literárias de períodos diferentes e de diferentes autores (brasileiros e estrangeiros), com a finalidade de levar o aluno a perceber como autores refletiam sobre os conceitos e, por meio de textos metalinguísticos, levar o aluno a compreender o processo criativo. Quanto aos autores, selecionamos: Machado de Assis, Franklin Távora, Fernando Pessoa, Thomas Mann, Ferreira Gullar e Paulo Leminski.

A escolha não foi exatamente aleatória, mas partiu-se do princípio de que o aluno do $2^{\circ}$ ano já teve contato com diversas concepções de literatura, ainda que não totalmente formado. O objetivo foi de perceber dois aspectos: como o público-alvo do processo/aprendizagem percebe aquilo que é ensinado para ele e qual a concepção que acaba por construir. Ora, há dois modos de se conceber a leitura: como decodificação do sentido e como construção do sentido. A literatura é, em sua essência, uma leitura que demanda a participação do leitor no processo de construção do sentido do que lê. É, pois, um processo interacionista. Vamos tratar melhor sobre esses aspectos a seguir.

\section{Fundamentação teórica}

Na década de 60, Hans Robert Jauss, como se sabe, procurou uma terceira via entre análise estética e a de base sociológica ou histórica. No caso, Jauss procurou refletir sobre o valor estético da recepção. Para tanto, determinou de que modo o leitor, não o individual, mas sim o paradigmático, aquele que indicaria um modo de ler uma obra em determinado período, em seu processo de leitura, contribuiria para o significado do texto consoante as mudanças no que o Jauss chamou de horizonte de expectativas.

A relação entre literatura e leitor possui implicações tanto estéticas quanto históricas. A implicação estética reside no fato de já a recepção primária de uma obra pelo leitor encerrar uma avaliação de seu valor estético pela comparação com outras obras lidas. A implicação histórica manifesta-se na possibilidade, numa cadeia de recepções, a compreensão dos primeiros leitores ser continuidade e enriquecer-se de geração em geração, decidindo, assim, o próprio significado histórico de uma obra e tornando visível sua qualidade estética. (JAUSS, 1994, p. 23). 
Um dos objetivos do pesquisador era revelar que o modelo de explicação da literatura por mudanças históricas, em uma sucessão de escolas literárias, erigido no século XIX, nunca dera conta, efetivamente, de explicar seu objeto, por dois motivos básicos: a escolha de determinadas obras, em tese representativas dos períodos ou escolas, não seria capaz de expressar o chamado espírito da época; era preciso emancipar uma obra do período de que faz parte, pois fica amarrada às características, para assim emancipar o leitor.

A função social da literatura só se manifesta em sua genuína possibilidade ali onde a
experiência literária do leitor entra no horizonte de expectativa de sua vida prática,
pré-forma sua compreensão do mundo e, com isso, repercute também em suas
formas de comportamento social. (JAUSS, 1994, p. 148).

É bastante conhecida também a palestra de Antonio Candido, em que ele fala sobre as três funções da literatura, dando destaque para a importância do leitor, do receptor da mensagem literária

[...] a ideia de função provoca não apenas uma certa inclinação para o lado do valor, mas para o lado da pessoa; no caso, o escritor (que produz a obra) e o leitor, coletivamente o público (que recebe o seu impacto). De fato, quando falamos em função no domínio da literatura, pensamos imediatamente (1) em função da literatura como um todo; (2) em função de uma determinada obra; (3) em função do autor, — tudo referido aos receptores. (CANDIDO, 1972, p. 1, grifo nosso).

Não é o objetivo aqui discutirmos as duas teorias, a da estética da recepção ou a das funções da literatura. O objetivo, antes, é o de usá-las como referência para promovermos a reflexão sobre o ensino da literatura.

Feitas essas considerações gerais em torno dos conceitos, reflitamos agora sobre nosso objeto, dando um destaque especial sobre a transposição didática de conceitos acadêmicos para a sala de aula e como isso serviu para cristalizar um tipo de aula fossilizada.

Para tanto, sirvamo-nos de um questionamento proposto por De Faria (2009, p. 1): “[...] por que os professores ensinam o que ensinam nas aulas de literatura, se há muito tempo o ensino de literatura pautado pela historicidade desvinculada dos textos é combatido?”

De acordo com os estudos de Souza (1999), desde o século XIX, com o surgimento do conceito de História e, particularmente, com o conceito de história literária, os estudos na área abandonaram as aulas baseadas em retórica e adotaram o modelo que, com algumas poucas mudanças, perdura ainda hoje nas salas de aula do Brasil. Lajolo e Zilberman (1998) também 
fazem referência a esse conteúdo ministrado nos colégios no século XIX e a mudança para os estudos históricos ainda naquele século, depois mais bem estabelecidos no século XX.

Em outros termos, os pesquisadores em questão (DE FARIA; SOUZA) demonstraram como se deu a transposição da historicização da literatura, realizada em meios acadêmicos, para as salas de aula como uma disciplina escolar, e como tal transposição, em rigor, mudou pouco desde o século XIX.

Outro aspecto importante a ser destacado por eles é que esse modelo pedagógico estava atrelado a um ensino voltado para as elites; porém, com a democratização da escola, especialmente com a Lei de Diretrizes e Bases de 1971, começou-se a pensar o ensino de maneira um tanto diversa.

Soares (2001) afirma, por exemplo, que a democratização trouxe consigo novos profissionais, igualmente advindos de camadas mais baixas da população, gerando mudanças no perfil do professorado. Tal professor precisou dar conta de um conteúdo, precisou também ter uma carga horária elevada para garantir um mínimo de ganho, impedindo-o de estudar ou pesquisar. Desse modo, esse professor tende apenas a repetir o que aprendeu e com quem aprendeu também. Geraldi (2003) destacou igualmente a mudança do perfil do professor das letras. Nesse conhecido estudo, Geraldi refere-se ao fato de o professor ter o perfil profissional não do pesquisador, e sim o que expressa, reproduz um conhecimento não produzido por ele próprio, ou seja, de produtor do conhecimento (pesquisador). Esse profissional, que se formou sobretudo a partir da década de 70, é quem reproduz o conhecimento gerado por outros, o que, por sua vez, levará os próprios alunos à condição passiva de receptores, não críticos, do que lhes é transmitido, para que possam igualmente transmitir a outros. A competência desse professor será então medida unicamente por sua capacidade de se atualizar ou não.

Embora os PCN (BRASIL, 2000) aparentemente apresentem uma concepção revolucionária de ensino de literatura, não há de fato uma sugestão de mudança efetiva na práxis no trabalho do professor. Ora, a simples determinação de incluir os estudos de literatura como um processo de desenvolvimento da leitura diz pouco. E, como se afirmou, como o professor tende a ser mais um transmissor que um produtor de conhecimento, a tendência é a repetição de um modelo de aula já erigido há tempos. Desse modo, pela 
confusão entre o que ensinar ou não, a tendência é ficar no universo conhecido. Por isso, a disciplina de literatura permanece tão histórica quanto aquilo que se ensina.

\begin{abstract}
O trabalho do professor centra-se no objetivo de desenvolvimento e sistematização da linguagem interiorizada pelo aluno, incentivando a verbalização da mesma e o domínio de outras utilizadas em diferentes esferas sociais. Os conteúdos tradicionais de ensino de língua, ou seja, nomenclatura gramatical e história da literatura são deslocados para um segundo plano. O estudo da gramática passa a ser uma estratégia para compreensão/interpretação/produção de textos e a literatura integra-se à área de leitura. (BRASIL, 2000, p. 18).
\end{abstract}

Literatura, antes de conteúdo, antes de ser uma disciplina escolar, é leitura, é desenvolvimento da capacidade de intelecção, por este motivo, considerá-la como leitura é bastante pertinente, mesmo porque é pela leitura que se dá o desenvolvimento do letramento literário; porém, apenas isso não basta, pois sempre existe o risco de se considerar a leitura literária segundo os mesmos parâmetros da leitura denotativa, por exemplo. Apesar de os PCN+ (BRASIL, 2002) reconhecerem a especificidade do discurso literário, há, nessa integração das disciplinas, o perigo de não se desenvolver o que se convencionou chamar de letramento literário, isto é, a competência de se ler um texto literário, de se conhecer e dominar as características de um poema ou de um romance.

O que norteou essa inclusão da literatura na área de leitura foi a mudança de paradigma proposto pela nova LDB, a lei 9.394/96, que deixou de separar o estudo da língua portuguesa do de literatura, como fazia a lei 5.692/71. Na prática, tal divisão não chegou de modo ainda determinante aos livros didáticos ou apostilas, que ainda apostam na divisão como meio de facilitar o estudo. Embora possa ser proveitosa a reflexão sobre os livros didáticos, não o faremos aqui. Importante ressaltar que o objetivo da integração é o de se proporcionar uma compreensão mais ampla da linguagem, como meio de interação sóciodiscursiva.

Apesar de toda essa discussão, profícua como iniciativa, a prática revela outra realidade. Uma causa para essa estagnação dos estudos literários no ensino médio talvez esteja nos vestibulares e mesmo no ENEM, que começou como meio de avaliar as competências desenvolvidas nos alunos do ensino médio, mas veio a se tornar apenas meio de acesso à Universidade. Com isso, mais do que desenvolver e avaliar as tais competências, o ENEM virou meio, não fim. 
Cereja (2005), por exemplo, faz uma ampla reflexão sobre a relação entre ensino de literatura e lista de livros para os vestibulares em geral. Os PCN e as Diretrizes Curriculares, em rigor, não levaram efetivamente o professor de literatura a uma mudança em sua práxis, por continuar a seguir práticas antigas, advindas do início do século XX, que é o de ensinar de acordo com a historicização literária (ainda que tenha sua validade), sem ensinar a ler uma obra literária, sem possibilitar ao educando o letramento literário.

Entre as competências a serem desenvolvidas pela disciplina de língua portuguesa, particularmente o estudo da literatura, citemos as seguintes:

\begin{abstract}
Analisar os recursos expressivos da linguagem verbal, relacionando textos/contextos, mediante a natureza, função, organização, estrutura, de acordo com as condições de produção, recepção (intenção, época, local, interlocutores participantes da criação e propagação das ideias e escolhas, tecnologias disponíveis). Recuperar, pelo estudo do texto literário, as formas instituídas de construção do imaginário coletivo, o patrimônio representativo da cultura e as classificações preservadas e divulgadas, no eixo temporal e espacial. (BRASIL, 2000, p. 24).
\end{abstract}

Se a primeira é mais abrangente, por incluir todo tipo de texto, a segunda é específica da leitura literária. Mas observe-se que a recomendação é usar da literatura como pretexto para outras finalidades (recuperar o patrimônio cultural), e não a leitura como meio de compreender o discurso literário por ele mesmo.

Nos PCN+, verifica-se o mesmo posicionamento:

Entender as manifestações do imaginário coletivo e sua expressão na forma de linguagens é compreender seu processo de construção, no qual intervêm não só o trabalho individual, mas uma emergência social historicamente datada. $\mathrm{O}$ estudo dos estilos de época, por exemplo, em interface com o dos estilos individuais, adquire sentido nessa perspectiva: a de que o homem busca respostas inclusive estéticas a perguntas latentes ou explícitas nos conflitos sociais e pessoais em que está imerso. (BRASIL, 2006, p. 49)

Importante lembrar que há nos $\mathrm{PCN}+$ a teoria da recepção, que aparecia de modo implícito no PCNEM. Bakhtin, Antonio Candido, Ítalo Calvino são alguns dos teóricos que sustentam a discussão sobre a importância do leitor. Nas Orientações Curriculares, Jauss é explicitamente citado. Entre as competências a serem desenvolvidas está exatamente a de levar o aluno a ser "protagonista na produção e recepção de textos" (BRASIL, 2002, p. 59, grifo nosso). Nesse sentido, a integração do ensino de literatura ao de leitura, com o objetivo de formar o leitor, leva-nos aos conceitos aludidos da Estética da Recepção, em que a 
historicização da literatura e seu consequente ensino deveriam ser relegados a segundo plano. Mesmo porque o fato de o aluno saber que houve uma escola chamada Romantismo, antecedida pela Era Clássica, e que mais adiante houve outra escola chamada Realismo etc. não leva, efetivamente, à formação do leitor. Por outro lado, é preciso que o aluno/leitor saiba perceber as razões das escolhas estéticas feitas por escritores em diferentes momentos, o que pressupõe a contextualização da obra.

\begin{abstract}
Acresça-se ainda o fato de que, se a história da literatura se desloca para segundo plano e a literatura se integra à leitura, então em que consistiria o novo ensino de literatura? O documento não deixa claro o que fazer com os textos literários nem que textos literários deveriam formar uma antologia a ser trabalhada em aula. $\mathrm{O}$ professor infere que deve deixar de lado a história da literatura e promover 'leituras' de textos literários, mas sob que critérios de seleção e organização? (CEREJA, 2005, p. 180).
\end{abstract}

Cereja (2005) apresenta em sua tese uma pesquisa realizada com estudantes de quatro escolas (duas pública, duas particulares) para determinar qual a percepção do aluno sobre aquilo que lhe é ensinado. Segundo o pesquisador, foram 134 respostas, as quais são interessantes para aquilo que vimos dizendo até aqui. Ora, se ensinar literatura é formar o leitor e levá-lo a perceber a especificidade do discurso literário, ao que parece, isso não tem sido realizado a contento, a julgar pelas respostas.

\title{
Gráfico 1: Para você, o que é literatura?
}

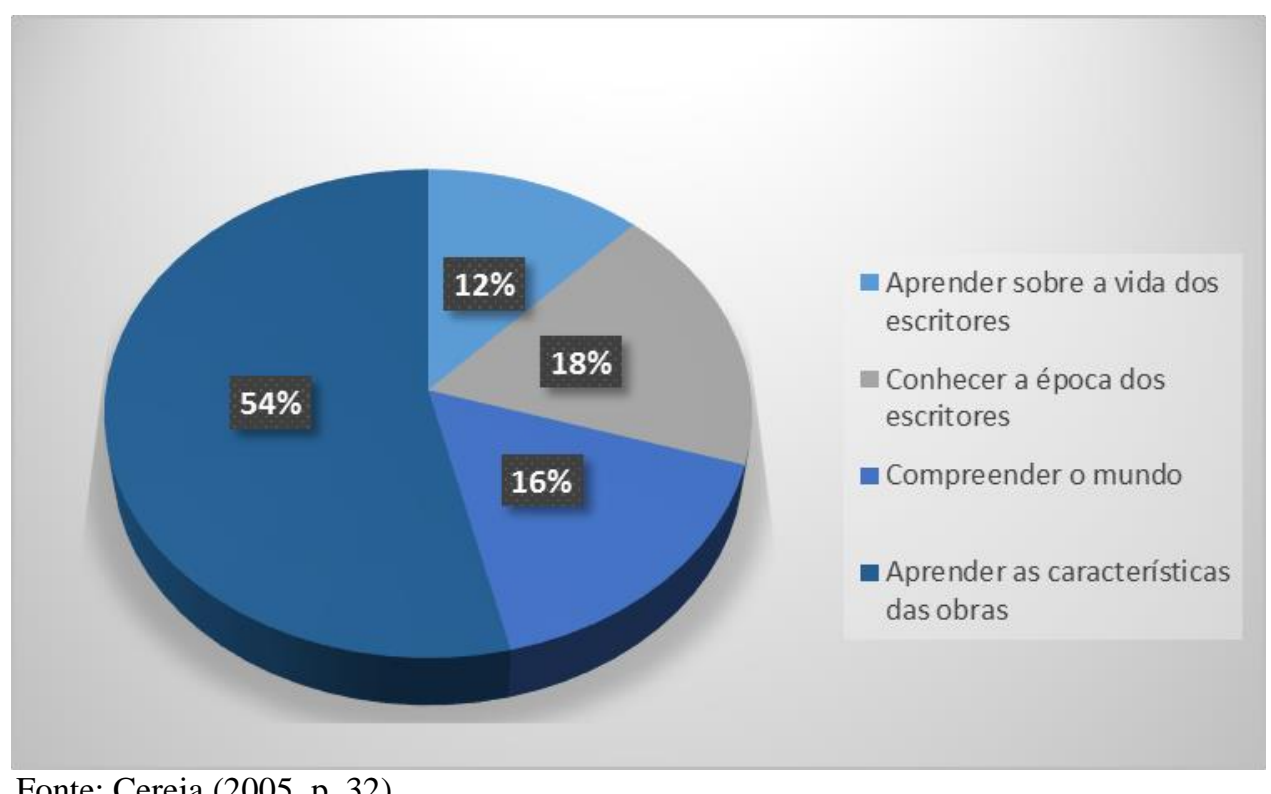

Fonte: Cereja (2005, p. 32). 
Em outros termos, para 70 alunos dos 134 que responderam, literatura é apenas uma disciplina, como biologia ou física. Apesar de a pesquisa ter sido realizada em 2004, certamente não haveria grande mudança se fosse realizada hoje novamente. De qualquer modo, logo adiante, especificaremos a percepção do aluno de uma escola pública, fazendo a pergunta de maneira mais aberta. $\mathrm{O}$ aluno tende a ver a educação, a escola como obrigação (pela necessidade de obter notas, fazer trabalhos, provas etc.) A literatura não fica imune a esse processo. Por isso mesmo, literatura, como qualquer outra disciplina, é vista como uma atividade curricular, não como meio de ter uma experiência estética.

Reproduzamos, entre outros que Cereja fez, um segundo questionamento que nos interessa mais de perto. No caso, ele quis saber do alunado, para que serviria o estudo da literatura.

\section{Gráfico 2: Para você, estudar literatura serve para:}

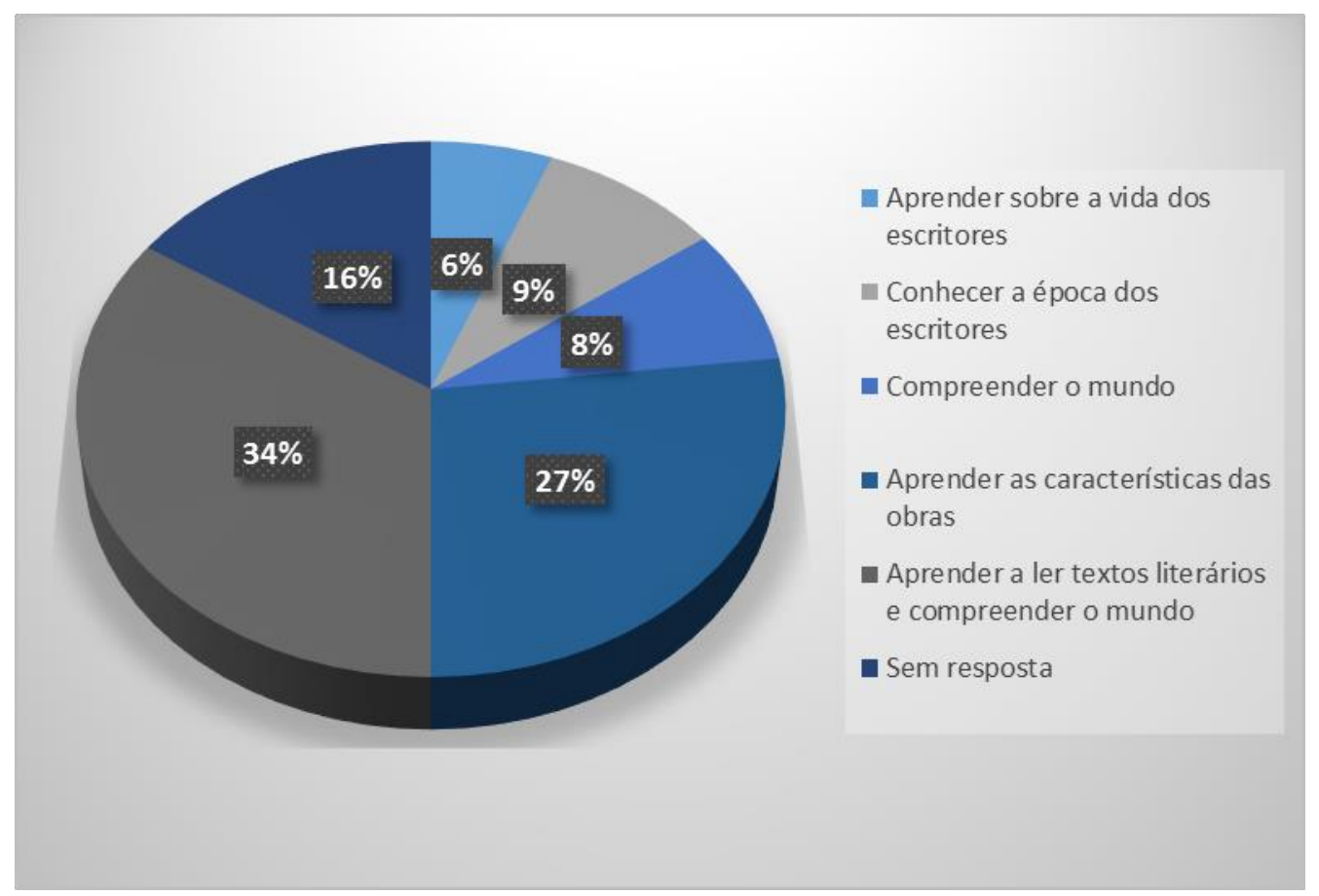

Fonte: Cereja (2005, p. 33).

Nessa segunda pergunta, a alternativa mais assinalada expressou uma visão adequada ao que se espera dos alunos em processo de formação como leitores, no caso estudar literatura é meio de aprender a ler textos literários. Porém, a maioria absoluta (66\%) assinalou outras 
respostas, se não mais corretas, ao menos as mais condizentes com o que efetivamente se estuda em sala de aula: características, vida e obra de autores e literatura como pretexto.

$\mathrm{O} \mathrm{PCN}+$ é de 2002. Neste documento, apesar da referência ao estudo da literatura como pretexto, verifica-se também a preocupação com a formação de leitores de textos literários. É a mesma visão presente nas Orientações Curriculares para o ensino médio, de 2006, em que se verifica uma ênfase no aluno para que seja levado a perceber o que é ou não literário, bem como à ideia de fruição estética. Desse modo, cumpre-se outro conceito expresso nas competências a serem desenvolvidas no século XXI, que é o aprender a aprender. Cabe, pois, ao professor estimular o aluno a refletir sobre os conceitos-chave da literatura: "Há ou não intencionalidade artística? A realização correspondeu à intenção? Quais os recursos utilizados para tal? Qual o seu significado histórico-social? Proporciona ele o estranhamento, o prazer estético?". (BRASIL, 2006, p. 57).

E o que seria esse prazer estético? A resposta também pode ser encontrada nos documentos:

\begin{abstract}
Desfrute (fruição): trata-se do aproveitamento satisfatório e prazeroso de obras literárias, musicais ou artísticas, de modo geral bens culturais construídos pelas diferentes linguagens, depreendendo delas seu valor estético. Apreender a representação simbólica das experiências humanas resulta da fruição dos bens culturais. Podem propiciar aos alunos momentos voluntários para que leiam coletivamente uma obra literária, assistam a um filme, leiam poemas de sua autoria de preferência fora do ambiente de sala de aula: no pátio, na sala de vídeo, na biblioteca, no parque. (PCN, 2002, p. 64).
\end{abstract}

Umberto Eco divide os leitores em dois tipos: “O primeiro é a vítima, designada pelas próprias estratégias enunciativas, o segundo é o leitor crítico, que ri do modo pelo qual foi levado a ser vítima designada" (ECO, 1989, p. 101). Ora, capacitar o aluno para que tenha condições de se tornar o leitor crítico deve ser papel preponderante da escola. Somente assim os leitores serão dotados das competências propostas pelos diversos documentos oficiais, e aqueles cobrados nas avaliações gerais, como Saeb (Sistema de Avaliação do Ensino Básico), ENEM (Exame Nacional do Ensino Médio) e PISA (Programme for International Student Assessment).

Uma solução para escapar do esquema anacrônico de ensino da literatura, ou antes de sua história, e levar à formação efetiva do leitor seria a proposição de um ensino sincrônico, que não visasse ao simples estabelecimento entre autores, obras, características, e sim que possibilitasse a uma compreensão mais ampla daquilo a que Chartier (1999) também fez 
referência, no caso conceber a literatura como um modo de expressão pensada com base em três elementos fundamentais que a constituem: o texto, o suporte e o leitor.

A ênfase no leitor parece, pois, o caminho para sua própria formação, sem esquecer a mediação do professor, responsável pela ponte entre texto e leitor.

Para encerrar a fundamentação, importante dizer que há diversas pesquisas que discutem as mudanças ocasionadas pelos PCN, bem como pela insatisfação com o ensino historicizante da literatura, que impede, de modo mais efetivo, o letramento literário do alunado. Entre essas pesquisas, além das referenciadas anteriormente, citemos: Zinani e Santos (2014); Lopes, Costa e Sampaio (2011); Ramos e Zanolla (2008).

\section{Metodologia/Resultados}

Considerando o que vimos afirmando até aqui, particularmente sobre o desenvolvimento do leitor de textos literários e sobre a necessidade de o aluno deixar a passividade de apenas receber o conteúdo pronto a fim de buscar a construção de conceitos, desenvolvemos uma sequência de atividades em um colégio estadual, com duas turmas do $2^{\circ}$ ano do ensino médio, sob permissão da professora regente. No caso, a atividade consistiu em levar os alunos a conceituarem três pontos dos estudos literários: a definição de literatura, as funções de literatura e o processo de construção do personagem. Para tanto, não utilizamos nenhum referencial teórico pré-definido, e sim solicitamos aos alunos que partissem da análise de alguns trechos de obras literárias, para analisarem o que diziam os autores em seus textos literários.

Para a definição de literatura, utilizamos o conhecido poema de Fernando Pessoa (2004), “Autopsicografia", e os capítulos I e LXXI, de Memórias Póstumas de Brás Cubas, de Machado de Assis (1997). Por serem textos metalinguísticos, o objetivo é que os alunos pudessem perceber no poema e nos capítulos a visão dos autores sobre seu próprio métier. A partir dessa perspectiva, foi solicitado que cada aluno escrevesse o que achava que seria literatura. Excluindo-se as cópias alheias (comuns em atividades em sala de aula), obtivemos 59 respostas discursivas, das quais destacamos a repetição de algumas palavras-chave. 


\section{Quadro 1: definição de literatura}

\begin{tabular}{|l|r|}
\hline O que é literatura & $\mathbf{5 9}$ alunos \\
\hline Arte & 24 \\
\hline Modo de expressão & 24 \\
\hline Leitura & 12 \\
\hline Saber/conhecimento & 11 \\
\hline Escrever bem & 6 \\
\hline Essencial para a vida & 6 \\
\hline Comunicação & 5 \\
\hline Criação & 3 \\
\hline Não gosto & 2 \\
\hline Escrever o que gosta & 2 \\
\hline É poesia, história & 2 \\
\hline Estudo das escolas & 2 \\
\hline literárias & \\
\hline Interpretar & 1 \\
\hline Escrita sem sentido & 1 \\
\hline Distração & 1 \\
\hline É tudo & 1 \\
\hline
\end{tabular}

Ao contrário da pesquisa realizada por Cereja (2005), que já continha as possibilidades de respostas, aqui o aluno era livre para se expressar, era livre para definir de acordo com o que havia estudado até então, bem como havia sido estimulado pela leitura de textos literários, independente da escola a que pertencem, da época em que foram escritos ou mesmo do país natal do autor. Embora essas informações possam ser importantes em determinado projeto pedagógico, o objetivo é que os alunos fossem estimulados a pensar na definição de literatura pela análise de dois textos. Evidente, há que se fazerem ressalvas, entre elas o fato de se terem trabalhado apenas dois textos etc.; o importante a se ressaltar é que o aluno foi estimulado a construir o conceito com base em leituras de textos literários.

O número de palavras-chave é maior que 59, por razão óbvia de que destacamos os termos de cada texto dos alunos. Como resultado, destaque-se que $40 \%$ das respostas revelaram a percepção dos alunos quanto à especificidade artística, dando destaque para o fato de a literatura ser uma arte e também um meio de expressão (de sentimentos, de ideias). 
A simples referência à palavra-chave "arte" pode indicar uma obviedade, por isso reproduzimos a seguir trechos dos textos escritos pelos alunos:

> Acredito que literatura é a arte da palavra, onde com esta é possível fazer o que quisermos, sem importar a finalidade.

É uma arte de escrever, de ir mais longe com nossas imaginações.

> Literatura para mim é uma forma de expressão que nos traz liberdade para retratar a realidade ou para usar a imaginação.

Como se pode perceber, a ênfase das respostas recaiu sobre definições da literatura como expressão artística, embora considerem a literatura como meio de transmissão de conceitos, como meio de propagar o conhecimento (onze respostas), ou consoante ainda o princípio retórico de literatura como espaço privilegiado do escrever bem (seis respostas). Também é possível perceber duas respostas que não conseguem transpor as paredes da sala de aula (estudo das escolas literárias) e outras que não definem, antes expressam juízos de valor: "é tudo", "é essencial para a vida", "não gosto", "escrita sem sentido".

$\mathrm{Na}$ segunda atividade, os alunos tiveram que determinar as funções da literatura. Candido (1972) vê a literatura com três funções: psicológica, formativa e também a função de conhecimento do mundo e do ser. Não era o objetivo que os alunos tivessem contato com esse referencial, e sim que formulassem sua própria teoria, mais uma vez com base na leitura de textos literários. Para isso, lerem quatro poemas: Ouverture la vie en close e O tempo fica, de Paulo Leminski (2013); Não há vagas e traduzir-se, de Ferreira Gullar (2004).

Destacamos 61 textos (mais uma vez descartando-se as simples cópias alheias), e observamos as seguintes palavras-chave:

\section{Quadro 2: Funções da literatura}

\begin{tabular}{|l|r|}
\hline Funções da literatura & 61 alunos \\
\hline $\begin{array}{l}\text { Fazer } \\
\text { conhecer/pensar }\end{array}$ & 32 \\
\hline Expressar sentimentos & 25 \\
\hline Transmitir ideias & 23 \\
\hline Estimula a imaginação & 11 \\
\hline Ensinar & 10 \\
\hline Autoconhecer-se & 8 \\
\hline Explicar épocas & 7 \\
\hline
\end{tabular}




\begin{tabular}{|l|l|}
\hline Linguagem & 3 \\
\hline Torna o leitor livre & 3 \\
\hline Identificar-se & 2 \\
\hline Informar & 2 \\
\hline Conforta & 1 \\
\hline Contar uma boa & 1 \\
\hline história & \\
\hline Divertir & 1 \\
\hline Faz bem & 1 \\
\hline
\end{tabular}

As palavras-chave destacadas das respostas dos alunos apresentam um caráter formativo (ensinar, explicar épocas, transmitir ideias, informar), um caráter psicológico (autoconhecer-se, identificar-se, tornar o leitor livre, estímulo à imaginação) e um caráter de levar ao conhecimento do mundo e do ser (fazer conhecer/pensar), o que aproxima a perspectiva dos alunos, ainda em processo de formação, daquela expressa por Candido. Mais uma vez, o que importa não é tanto estabelecer as semelhanças de perspectiva, e sim revelar que o aluno, quando estimulado, pode dar respostas pertinentes, e, principalmente, cumprir os desafios do processo ensino/aprendizagem de modo satisfatório. Leia-se: desenvolver as competências de um leitor eficiente, particularmente do leitor de textos literários.

Por fim, para que pudessem compreender o processo de criação de uma personagem, solicitamos aos alunos que lessem o início do capítulo 1, de $O$ Cabeleira, de Franklin Távora (2003), e trecho de Morte em Veneza, de Thomas Mann (2003), em que Aschenbach descreve Tadzio. São trechos metalinguísticos, uma vez que os respectivos narradores tratam sobre a construção do personagem. Se José Gomes, o Cabeleira, está distante no tempo do narrador, Tadzio está diante dos olhos de Aschenbach. Com isso, o objetivo é que os alunos observassem como cada escritor trata sobre esse olhar. Motivados pelo que se apresentava nos trechos aludidos, os alunos destacaram o seguinte:

\section{Quadro 3: Criação de personagem}

\begin{tabular}{|l|r|l|r|}
\hline Criação do personagem & 65 alunos & & \\
\hline Morte em Veneza & & O Cabeleira \\
\hline Realidade ideal & 33 & Tradição oral & 43 \\
\hline Baseado na observação & 17 & Fatos & 30 \\
\hline Pura imaginação & 5 & Trovadores & 22 \\
\hline Realidade & 5 & Observação & 2 \\
\hline
\end{tabular}


Igualmente fomos obrigados a descartar as cópias alheias. O objetivo dessa última atividade é que o aluno pudesse ler uma obra literária com outra perspectiva, com a perspectiva que indica o processo criativo de um texto literário. Em outras palavras, o letramento literário deve também permitir que o leitor tenha uma percepção sobre como um texto literário (aqui especificamente a criação do personagem) pode ser criado. É o princípio do leitor crítico a que faz referência Eco (1989) e também, com outros objetivos, Wolfgang Iser (1979), para quem cabe ao leitor, na interação com o tex to literário, descobrir aquilo que não é explícito, descobrir as intenções subjacentes desse tipo de texto, uma vez que, ao contrário de outros gêneros textuais, o literário trata do real, sem falar especificamente do mundo real. Assim, ao criar um personagem baseado na observação real ou em informações históricas (escritas ou da tradição oral), sua intenção é o de reconstituir a pessoa que se foi ou a pessoa ideal? Não chegamos a tratar de modo tão aprofundado em sala de aula, no entanto os alunos puderam, pela leitura, perceber as possibilidades criativas.

\section{Considerações finais}

Neste artigo, procuramos contextualizar a discussão em torno da urgência de se mudar o modo de ensinar a literatura, alterando seus objetivos, em busca do real desenvolvimento do leitor, tal e qual propõem os PCN.

Como objetivo, propôs-se refletir sobre como o público-alvo do processo/aprendizagem percebe aquilo que lhe é ensinado, no caso o estudo da literatura, e qual a concepção de literatura que constrói.

Em conclusão, pôde-se perceber que o alunado demonstrou, mesmo sem conhecimento técnico, perceber as funções da literatura, bem como possíveis concepções do fazer literário, com base não na relação teoria/prática, mas sim na relação prática de leitura e construção teórica. Evidente que não podemos afirmar que todos os alunos cumpriram plenamente a tarefa proposta, e sim que se buscou uma compreensão do literário por meio da análise de textos de escritores (romancistas e poetas) selecionados.

Com isso, procurou-se demonstrar que o aluno, uma vez estimulado, tende a responder de maneira satisfatória aos desafios que lhe são propostos. O que incomoda o aluno, para além 
de ser mais cômodo, é a passividade que é obrigado a assumir nas aulas de literatura, em que tende apenas a ouvir as histórias do professor que reconta a história da literatura. Aqui, buscou-se o desenvolvimento de conceitos importantes para o discurso literário, embora se pudesse igualmente propor outras atividades.

O importante é demonstrar a possibilidade de quebra da passividade por parte do alunado com outro tipo de ensino, que tem outros objetivos, que não apenas o de se preparar para um exame vestibular ou coisa que o valha.

\section{Referências bibliográficas}

ASSIS, Machado. Memórias póstumas de Brás Cubas. In: Obra completa. Rio de Janeiro, RJ: Nova Aguilar, 1997. v. 1

BAKHTIN, Mikhail. Problemas da poética de Dostoiévski. 2. ed. Rio de Janeiro, RJ: Forense Universitária, 1997.

BELLONI, Maria Luiza. O que é mídia-educação. 2. ed. Campinas, SP: Autores Associados, 2005.

BRASIL. Parâmetros curriculares nacionais: introdução aos parâmetros curriculares nacionais. Brasília: MEC/SEF, 1997. V. 1

Parâmetros Curriculares Nacionais: Ensino Médio. Linguagens, códigos e suas tecnologias. Brasília: MEC, 2000. Parte II.

Parâmetros Curriculares Nacionais+: Ensino Médio. Orientações Educacionais

Complementares aos Parâmetros Curriculares Nacionais. Linguagens, códigos e suas tecnologias. Brasília: MEC, 2002.

Orientações curriculares para o ensino médio: linguagens, códigos e suas

tecnologias. Brasília: MEC/SEF, 2006. V. 1.

CANDIDO, Antônio. A literatura e a formação do homem. Ciência e Cultura. 24 (9): 803809, set, 1972. Disponível em

<http://revistas.iel.unicamp.br/index.php/remate/article/viewFile/3560/3007> Acesso em: 10 nov. 2014.

CEREJA, William Roberto. Ensino de literatura: uma proposta dialógica para o trabalho com literatura. São Paulo, SP: Atual, 2005.

CHARTIER, Roger. A ordem dos livros. Brasília, DF: Unb, 1999. 
DE FARIA, Vanessa Fabíola Silva. O ensino de literatura e a formação do leitor literário: entre saberes, trajetórias de uma disciplina e suas relações com os documentos oficiais Revista Iberoamericana de Educación, n. ${ }^{\circ}$ 49/7, p. 1-12, 25 jun. 2009.

ECO, Umberto. O texto, o prazer, o consumo. In: . Sobre os espelhos e outros ensaios.

Rio de Janeiro, RJ: Nova Fronteira, 1989.

GERALDI, João Wanderley. Portos de passagem. 4. ed. São Paulo, SP: Martins Fontes, 2003.

GULLAR, Ferreira. Toda poesia. 16. ed. Rio de Janeiro, RJ: José Olympio, 2004.

KLEIMAN, A. Os significados do letramento. Campinas, SP: Mercado das Letras, 1995.

ISER, Wolfgang. A interação do texto com o leitor. In: LIMA, Luis Costa. A literatura e o leitor: textos da Estética da Recepção. Rio de Janeiro: Paz e Terra, 1979. p. 83-182.

INSTITUTO Pró-livro. Retratos da leitura no Brasil. São Paulo, 2012. Disponível em: $<$ http://prolivro.org.br/home/images/relatorios_boletins/3_ed_pesquisa_retratos_leitura_IPL.p df> Acesso em: 10 nov. 2014.

LAJOLO, Marisa; ZILBERMAN, Regina. A formação da leitura no Brasil. 3. ed. São Paulo, SP: Ática, 1998.

LEMINISKI, Paulo. Toda Poesia. São Paulo, SP: Cia. das Letras, 2013.

LOPES, Larissa Cristina Viana; COSTA, Maria Edileuza da; SAMPAIO, Maria Lúcia Pessoa. Letramento Literário e formação do professor: o ensino de literatura no meio universitário. Entreletras: Revista do Curso de Mestrado em Ensino de Língua e Literatura da UFT, nº 3, p. 63-80, 2011-2.

MANN, Thomas. Morte em Veneza. São Paulo, SP: Folha de S. Paulo, 2003.

PESSOA, Fernando. Mensagem. In: Obra poética. Rio de Janeiro, RJ: Nova Aguilar, 2005.

PIAGET, Jean. Epistemologia genética. Trad. de Álvaro Cabral. 3. ed. São Paulo, SP: Martins Fontes, 2007.

RAMOS, Flávia Brocchetto; ZANOLLA, Taciana. Repensando o ensino de literatura no Ensino Médio: a interação texto-leitor como centro. Contrapontos, Itajaí, V. 9 n ${ }^{\circ}$ 1, p. 65-80 jan/abr., 2009.

SOARES, Magda B. Letramento: um tema em três gêneros. 2. ed. Belo Horizonte, MG: Autêntica, 2006. 


\section{9}

SOUZA, Roberto Acízelo de. O império da eloquência: retórica e poética no Brasil Oitocentista. Rio de Janeiro, RJ: Eduerj/Eduff, 1999.

TÁ VORA, Franklin. O Cabeleira. São Paulo, SP: Martin Claret, 2003.

ZINANI, Cecil Jeanine Albert; SANTOS, Salete Rosa Pezzi dos. Ensino de literatura: possibilidades e alternativas. Disponível em <www.pucrs.br/edipucrs/CILLIJ/praticas/Ensino_de_literatura_.pdf> Acesso em 10 nov. 2014. 